\title{
Unit of Magnetic Flux Density
}

National Cancer Institute

\section{Source}

National Cancer Institute. Unit of Magnetic Flux Density. NCI Thesaurus. Code C68794.

A unit of measurement of the amount of magnetic flux per unit area of a section,

perpendicular to the direction of flux. 